\title{
The effect of pressure and frequency on the dynamic behavior and evaporation time of successive water droplets impacting onto hot surface
}

\author{
Teguh Wibowo ${ }^{1,3^{*}}$, Arif Widyatama ${ }^{1}$, Samsul Kamal ${ }^{1,3}$, Indarto ${ }^{1}$, and Deendarlianto ${ }^{1,2}$ \\ ${ }^{1}$ Department of Mechanical \& Industrial Engineering, Universitas Gadjah Mada, J1. Grafika No.2 Yogyakarta, Indonesia. \\ ${ }^{2}$ Center for Energy Studies, Universitas Gadjah Mada, Sekip Blok K 1A, Kampus UGM, Bulaksumur, Yogyakarta, Indonesia \\ ${ }^{3}$ Department of Mechanical Engineering, Sekolah Tinggi Teknologi Adisutjipto, Jl. Janti Blok R. Lanud, Yogyakarta, Indonesia.
}

\begin{abstract}
Multiple droplets are the drop of water which continuously dropped on a surface in certain time difference. The phenomenon droplets impacting a solid surface can be found in a various field, one of them is the cooling process in the metal industry. The cooling process is carried out by spraying a number of water droplets to hot surface until it reaches the desired condition. When droplets impinge on the surface, the dynamics of droplets, such as the spreading and recoil phenomena, depend on some properties. In this study, the effect of pressure and drop frequency to the droplet characteristics as well as cooling effectiveness will be investigated. Visualization process is used to find maximum spreading which can indicate the effectiveness of hot surface cooling. The experiment is performed by setting the distance of water tank and nozzle into $100 \mathrm{~cm}, 150 \mathrm{~cm}$ and $200 \mathrm{~cm}$ while the frequency of droplets is set at 245,386 , and 623 drops $/$ minute. The material used in the present work is Stainless Steel with the temperature ranged from $100^{\circ} \mathrm{C}-220^{\circ} \mathrm{C}$. In addition, image processing technique is applied to gather the quantitative data from the images that successfully taken by using high-speed camera. Based on the study, it is found that the pressure of water tank affects the frequency of generated droplet. Furthermore, the frequency of droplet impacting onto the hot surface also influences the evaporation time.
\end{abstract}

\section{Introduction}

The application of multiple droplets on numerous industrial field has grown massively nowadays. For instance, in the material industry, spray cooling method is usually utilized in quenching process of metal since this method is able to distribute the heat better than the conventional method. As a result, it provides some benefits such as reducing the production cost and improving the accurateness as well as the efficiency of cooling process on high-quality metal forming which will significantly affect the profitability of the final product [1].

To obtain in depth understanding related to those phenomena, comprehensive study is essentially needed. Based on several previous research, it is noted that characteristics of spray cooling, such as the bubble dynamics and transient heat transfer, can be investigated by successive multiple droplet approaches. In addition, [2] has revealed that the deformation behavior of a single droplet impacting on a hot solid surface is affected by various factors, such as impact velocity and pre-impact diameter of droplet, liquid viscosity, surface tension, wettability between liquid and solid surface, liquid and solid temperatures, roughness of solid surface, and impact angle. Increasing impact velocity enhances heat flux from the substrate by only a small amount [3].

Kandiklar et al. [4] have investigated the effect of Webber number on the characteristics of droplet impinging on the solid surface. This research focused on the observation during droplet levitation and has classified that phenomena into four types. Furthermore, the phenomena of hydrodynamics and boiling phenomena of water droplet have been studied by Fujimoto et al [5]. It covers various condition (impact velocities, droplet diameters, and temperatures) and used high speed camera to observe the behavior of droplet and the presence of secondary droplet. However, the previous research has focused on the phenomena of single droplet while in real situations, the droplets usually impact upon a hot solid surface in the form of successive multiple droplets. Therefore, the comprehensive study related to multiple droplets should be conducted.

The objective of the present study is to investigate the effect of pressure and frequency to the dynamic behavior and heat transfer phenomena of successive water droplets impacting on to hot surface. The material used in this present study is stainless steel. The visualization by using

${ }^{*}$ Corresponding author: teguhwibowo76@yahoo.co.id 
high speed video camera, supported by image processing technique, is applied in order to reveal the specific phenomena comprehensively.

\section{Experimental apparatus and procedure}

Figure 1 depicts the schematic of the experimental apparatus to observe the dynamic behavior of multiple successive droplets on a hot solid surface. It is placed in Fluid Mechanics Laboratory of the Department of Mechanical and Industrial Engineering, Universitas Gadjah Mada and generally consists of droplet generator, hot surface, an illumination system, a high-speed video camera, and personal computer.

The droplet generator consists of two main parts, the water tank, as a water storage, and droplet injector. The position of the water tank can be adjusted in vertical axis to observe support the aim of this study. In the present work, the height of tank is set on $100 \mathrm{~cm}, 150 \mathrm{~cm}$, and 200 $\mathrm{cm}$. Furthermore, the droplet diameter and the distance of droplet injector from hot surface are $2.8 \mathrm{~mm}$ and $70 \mathrm{~mm}$, respectively. To observe the phenomena of multiple successive droplets clearly, a high-speed video camera is utilized and set on 1000 fps and very low shutter speed. The produce bright and optimal visualization, a set of LED lamp, is also installed in particular position.

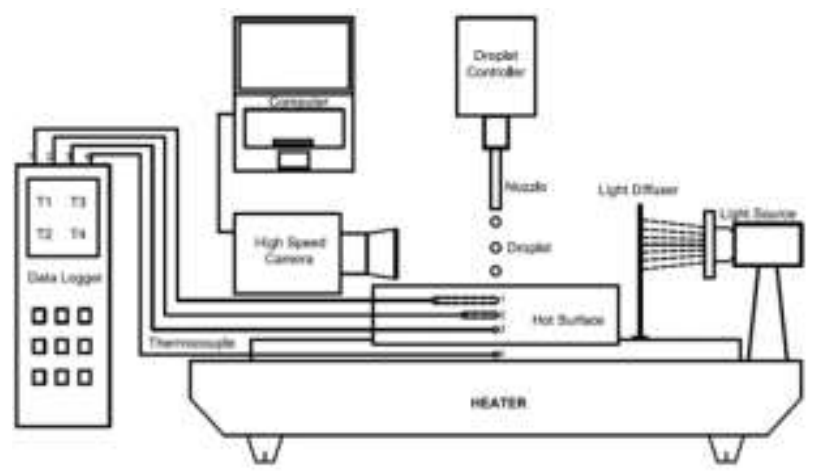

Fig 1. The schematic drawing of experimental apparatus
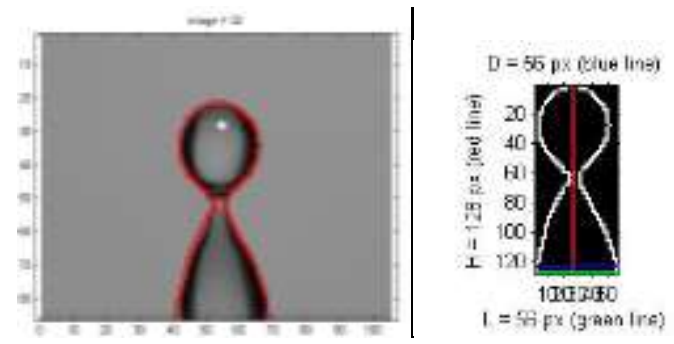

Fig 2. The example of image processing result

In the present study, stainless steel is used as experiment specimen. It is placed on the induction heater to achieve the desired hot solid surface condition which is set in $100^{\circ} \mathrm{C}, 140^{\circ} \mathrm{C}, 180^{\circ} \mathrm{C}$, and $220^{\circ} \mathrm{C}$. The benefit of this heater is the ability to adjust the temperature easily and can reach the experimental temperature fast. In general, the experimental condition used in this study is briefly shown in Table 1.
After the experimental data is recorded, the multiple figures of multiple droplets are processed through image processing technique. In this method, sequence steps are applied to raw images to produce binary image. The binary image is an image which only consists of two color, black and white, representing the background and the droplet. Therefore, the dynamics of the droplet can be identified. Figure 2 shows the final result of image processing technique utilized in present work. Based on the figure, it is noted that the boundary of the bubble can be clearly described. As a result, the height and the spreading diameter of the bubble on the particular time can be calculated. Those parameters will be compared to the initial diameter $\left(\mathrm{d}_{\mathrm{o}}\right)$ and arranged in time series diagram.

Table 1. Experiment condition.

\begin{tabular}{ccc}
\hline $\begin{array}{c}\text { High Water } \\
\text { Tank }(\mathbf{c m})\end{array}$ & Weber Number & $\begin{array}{c}\text { Temperature } \\
\left({ }^{\circ} \mathbf{C}\right)\end{array}$ \\
\hline 100 & 61 & $100-220$ \\
150 & 61 & $100-220$ \\
200 & 61 & $100-220$ \\
\hline
\end{tabular}

\section{Result and discussion}

In the present work, the water tank is configured on three different height so the frequency will also change, too. Figure 3. Shows the different behavior which occurs on three different configurations.

When the water tank is set at $100 \mathrm{~cm}$ from the nozzle, first droplet and second droplet impact the hot surface with time difference at $195.5 \mathrm{~ms}$ and the gap increased consistently until the fourteenth droplet which reaches $260 \mathrm{~ms}$. On the fifteenth droplet, the frequency of droplet is almost stable since the time difference is quite similar.

Next, the similar behavior occurs when the water tank is set $150 \mathrm{~cm}$ from the nozzle. First, the time difference increase before it is stable on the fourteenth droplet. On the eighteenth droplet, there is a sudden increase of time difference. This phenomenon is caused by when the droplet valve has been closed, the potential energy of the water is still able to generate the droplet from the nozzle although it occurs in very slow frequency.

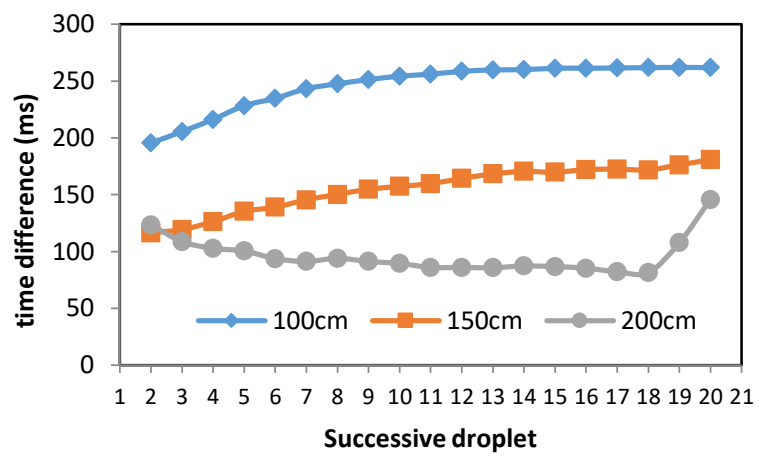

Fig 3. The effect of the position of water tank on the time difference between successive droplets

As the water tank is placed higher, on $200 \mathrm{~cm}$ from the nozzle, the droplet generator shows a different trend. After the first droplet hit the hot surface, the time 
difference between two consecutive droplets become shorter and reach the stable condition after the eleventh droplet is generated. At the end, it shows the same tendency with the droplet generated from the water tank which is set $150 \mathrm{~cm}$ from the nozzle due to the potential energy. Finally, based on the previous analysis, it is known that the frequency of droplet generated from the water tank placed on $100 \mathrm{~cm}, 150 \mathrm{~cm}$, and $200 \mathrm{~cm}$, are 4 dps (droplet per second), $6.4 \mathrm{dps}$, and $10.4 \mathrm{dps}$, respectively.

Figure 4 illustrates the time evolution of spreading ratio during the successive multiple droplets impacting on a hot surface where the water tank is placed $100 \mathrm{~cm}$ from the nozzle. Each line in the figure represents the surface temperature of $100,140,180$, and $220^{\circ} \mathrm{C}$. On $100^{\circ} \mathrm{C}$, it is apparent after the first droplet impacting the hot surface, the spreading ratio suddenly increase followed by some recoil and fluctuation before it starts to reach a stable condition. Furthermore, the presence of trailing droplet is able to raise the spreading ratio again. On $140^{\circ} \mathrm{C}$ the same trend is also found regarding the dynamic behavior of successive multiple droplets. However, the spreading ratio of $140^{\circ} \mathrm{C}$ is slightly higher than that of on $100^{\circ} \mathrm{C}$. Close observation on the figure also reveals that on $180^{\circ} \mathrm{C}$ and $220^{\circ} \mathrm{C}$, the fluctuation of spreading ratio appears clearly compared to the lower temperature.

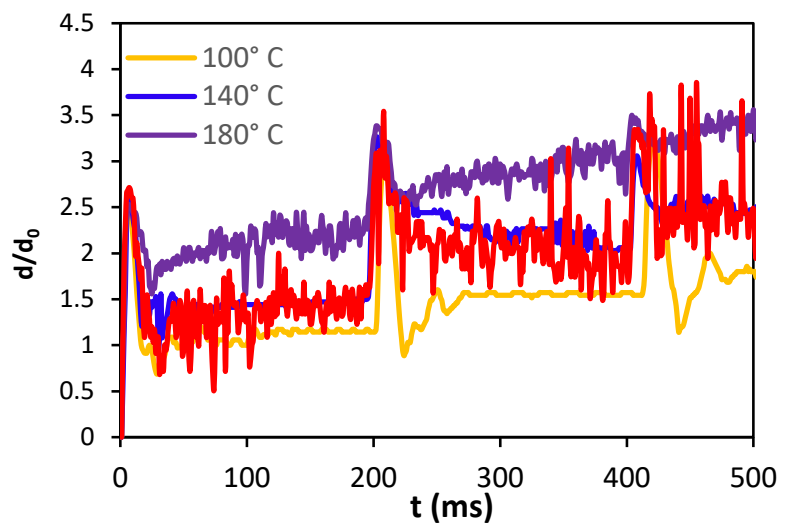

Fig 4. The effect of surface temperature on the evolution of spreading ratio of successive multiple droplets (height of water tank $=100 \mathrm{~cm}$ )

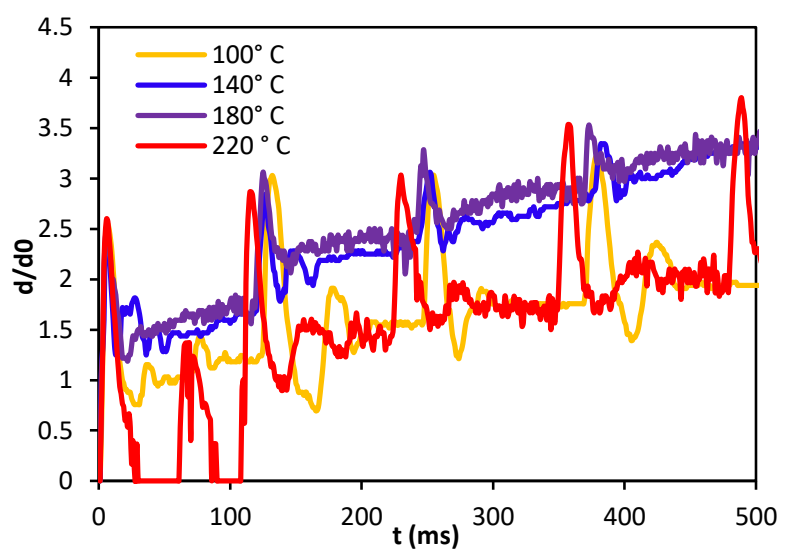

Fig 5. The effect of surface temperature on the evolution of spreading ratio of successive multiple droplets (height of water tank $=150 \mathrm{~cm}$ )
Figure 5 shows the time evolution of spreading ratio during the successive multiple droplets impacting on a hot surface where the water tank is placed $150 \mathrm{~cm}$ from the nozzle. In general, compared to Figure 4, the sudden increase of spreading ratio occurs more frequent as a result of the increase in the number of successive multiple droplets impacting the hot surface during the same time. The dynamic behavior of successive multiple droplets is similar to the previous case except on the $220^{\circ} \mathrm{C}$ where the bouncing phenomena occur several times. The result of this study shows good agreement with that of Bai and Gosman [6] which revealed the effect of Webber number on bouncing phenomena

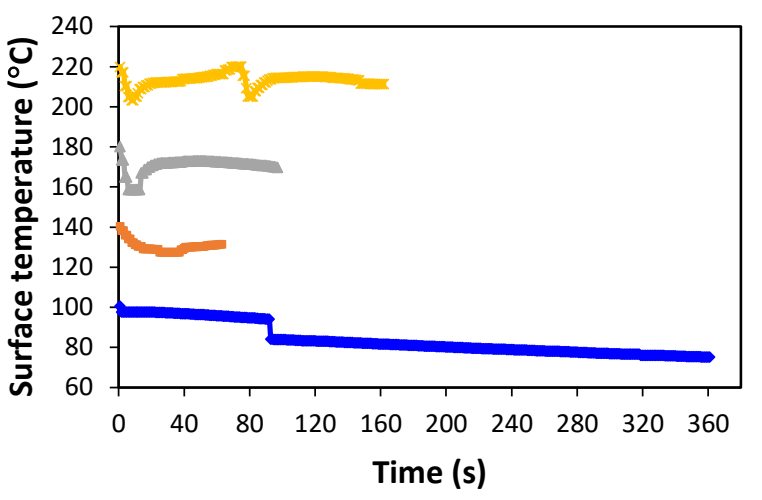

(a)

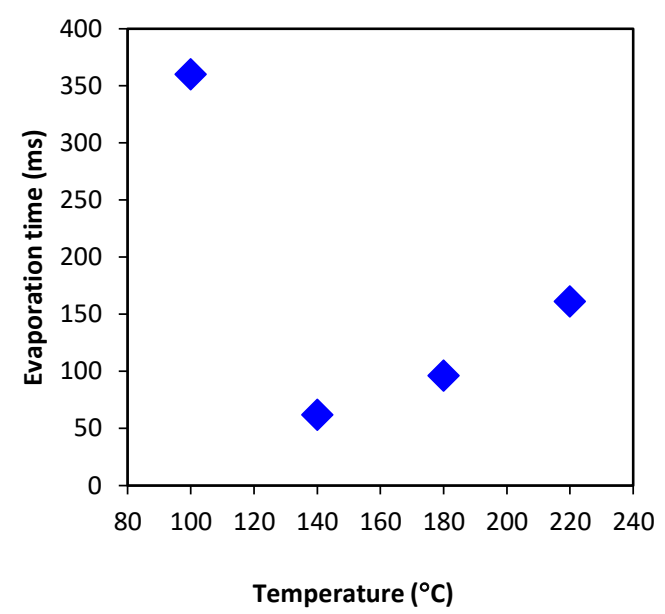

(b)

Fig 6. (a) Temperature-time history of a surface, (b) Evaporation time

Figure 6. (a) displays the temperature time history of stainless steel surface affecting by the presence of droplet on various surface temperature while the Figure 6. (b) shows the comparison of evaporation time after the successive multiple droplets impacting the hot surface on various temperature. The configuration of water tank placed $100 \mathrm{~cm}$ on the nozzle is chosen as an example. Based on the figure, it is observed that on $100^{\circ} \mathrm{C}$, it need around $360 \mathrm{~s}$ for droplet to perfectly evaporate. In addition, the fastest time occurs when the hot surface is set to $140^{\circ} \mathrm{C}$. This phenomenon is similar to the result of an experiment conducted Nukiyama [7], who found that the maximum heat flux occurs around $140^{\circ} \mathrm{C}$. On $180^{\circ} \mathrm{C}$ 
and $220^{\circ} \mathrm{C}$, it is also observed that the droplet generates small bubbles which affect the bubble shape. In addition, the numerous secondary droplet also occurs and separate them from the main droplet

\section{Conclusion}

In the present work, the effect of pressure on water tank on the dynamics of successive multiple droplets is investigated experimentally. An image processing technique is utilized to observe the droplet behavior. Based on the study, it is found that the pressure and frequency affect the behavior of droplet impacting the hot surface. The presence of multiple droplets can effectively enhance the wettability performance which is proved by the increase of spreading ratio of the droplet. The further study can be carried out in wide range area of frequency parameter. It is also possible to improve the presence of high-quality database by conducting the experiment in different material.

This present work was carried out within a research project funded by Directorate General of Higher Education, Ministry of Education and Culture, Republic of Indonesia

\section{References}

1. Deendarlianto, Yasuki, T., Sumitorno, H., Indarto, et al., Effect of Static Contact Angle on The Droplet Dynamics During The Evaporation of a Water Droplet on The Hot Walls, Int J Heat Mass Transf 71, pp.691 705, (2014)
2. Fujimoto H., A.Y. Tong, H. Takuda, Interaction phenomena of two water droplets successively impacting onto a solid surface. Int. J. Therm. Sci. 47, 229-236, (2008)

3. Pasandideh-F, S.D. Aziz, S. Chandra, J. Mostaghimi, Cooling effectiveness of a water drop impinging on a hot surface, Int. J. Heat Fluid Fl. 22, 201-210, (2001).

4. Kandlikar, S. G., Steinke, M. E., \& Singh, A.. Effects of Weber Number and Surface Temperature on the Boiling and Spreading Characteristics of Impinging Water Droplets. 35th National Heat Transfer Conference, (2001).

5. Fujimoto. H, Oku. Y, Ogihara. T, Takuda. H., Hydrodynamics and boiling phenomena of water droplets impinging on hot solid, Int J. Multiph. Flow 36, 620-642, (2010)

6. Bai, C., Gosman, A.D., Development of methodology for spray impingement simulation. Society Automot. Eng. 950283, 69-87, (1995).

7. Frank P. Incropera and David P. DeWitt, , Fundamentals of Heat and Mass Transfer, 3rd ed. This material is used by permission of John Wiley \& Sons, Inc, (1990) 